\title{
Study on the Law of Release of Heavy Metal from Waste Rock of Dexing Copper Mine
}

\author{
Qiong Wang ${ }^{1, a}$, Huiping Wang ${ }^{2, b}$, Qiming Wu ${ }^{2, c}$, Lianbi Zhou ${ }^{1, d^{*}}$ \\ ${ }^{1}$ Beijing General Research Institute of Mining \& Metallurgy, China \\ 2 Dexing Copper Mine of Jiangxi Copper Limited Corporation, China \\ awangqiong426@126.com, b531040484@qq.com, c327143101@qq.com, dzhoulianbi@aliyun.com
}

\begin{abstract}
Keywords: waste rock; heavy metals; leaching
Abstract. Release law of heavy metals from waste rock are significant to the heavy metal pollution control in nonferrous metal mining-area. We took the waste rock of Dexing Copper mine as the object and carried out the leaching experiment with with simulated acid rain(pH3.0, $\mathrm{pH} 4.0, \mathrm{pH} 6.0$ and $\mathrm{pH} 8.0)$ which were conducted to investigate the release law of heavy metals $(\mathrm{Cu}, \mathrm{Pb}, \mathrm{Zn}, \mathrm{Cd}$ and $\mathrm{As})$ from waste rock. The results of the experiments were as follows: Waste rocks have relatively acid producing capacity in natural rainfall; with the increase of $\mathrm{pH}$ value of added liquid, the electric conductivity reduces gradually, and the amount of heavy metal release reduces. The release process of 5 heavy metal elements $(\mathrm{Cu}, \mathrm{Pb}, \mathrm{Zn}, \mathrm{Cd}$ and $\mathrm{As})$ from the waste rocks can be classified into two stages, i.e. rapid release stage and slow release stage. They are the mostly easily to be released and migrated under the action of strong acid with the lowest $\mathrm{pH}$, and the leaching quantity is relatively low if leached by leachate with $\mathrm{pH}$ nearly neutral.
\end{abstract}

\section{Introduction}

Natural rainwater penetrating into waste rock dumps can accelerate or inhibit the occurrence of a variety of chemical reactions as the substances and the acidity and alkaline contained in the rainwater change the internal environment of the waste rock dump and damage the original reaction equilibrium. Some scientific research reveals acid rain improves the dissolution and release of heavy metal ions and other hazardous elements, acidic leachate can eminently increase the release speed and concentration of heavy metal ions in the waste rock dump, and the $\mathrm{pH}$ value of acid rain has certain correlation with the leaching concentration of heavy metals in waste rock dumps ${ }^{[1-3]}$. A large number of scientific experiments revealed that common acidic leaching may accelerate the leaching of heavy metal ions ${ }^{[4-6]}$.

According to the rainfall monitoring data in recent 5 years, Dexing City is a high incidence areaof acid rain, and the $\mathrm{pH}$ of rainfall falls between 3.93-6.81. To achieve full knowledge of the law and characteristics of leaching of heavy metals in the tailings under natural rainfall of Dexing City, this experiment adopts the method of simulated acid rain leaching to explore the law of variation of heavy metal contents in the leachate over time.

\section{Materials and methods}

Objects of study. Fresh ores of Dexing Copper Mine is selected as the study objects $(\leqslant 1 \mathrm{a})$, and the samples are not less than $25 \mathrm{~kg}$.

Experiment design. Variable parameters considered in the experiment include $\mathrm{pH}$, temperature, time and leachate flux, etc. The initial condition for experiment chosen is similar to the conditions of natural environment and acid rain: temperature selected: $20-30^{\circ} \mathrm{C}$, leachate of four acidities $(\mathrm{pH}$ values of 3, 5,6 and 8) are prepared.

Preparation of leachate: water samples with $\mathrm{pH}$ values of 3, 5, 6 and 8 are prepared with distilled water, and respectively tagged as $\mathrm{pH}_{3}, \mathrm{pH}_{5}, \mathrm{pH}_{6}$ and $\mathrm{pH}_{8}$.

Leaching device: As shown in Fig 1, the leaching column is $80 \mathrm{~cm}$ in length, diameter $6 \mathrm{~cm}$, and $5 \mathrm{~cm}$ quartz is put onto the bottom of the column, and then waste rock samples are added. 


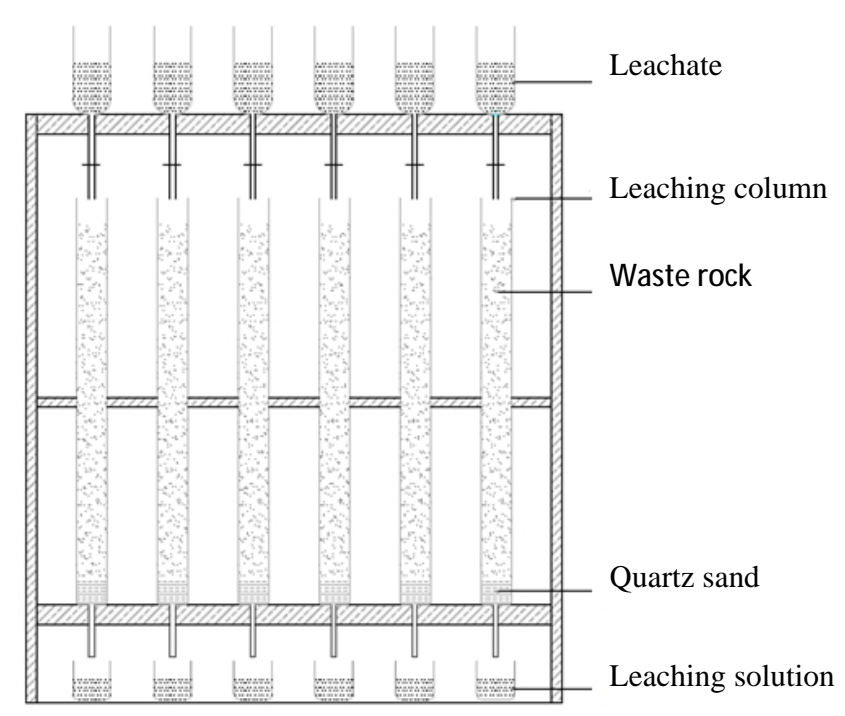

Fig 1 Leaching experiment device

In order to reduce experimental errors, each leachate is repeated three times. Four types of leachate and 12 leaching columns in total are taken. The $\mathrm{pH}$ and electric conductivity of each group of water samples are measured every 24 hours, and the contents of heavy metals in the leachate are measured on the 1st, 7th, 14th, 30th, 45th, 60th and 75th days respectively.

\section{Results and analysis}

Law of $\mathbf{p H}$ variation of leachate over time. As can be seen in Fig 2, the $\mathrm{pH}$ value of leachate is very low under leaching of different $\mathrm{pH}$ values, the maximum value is only 1.87; if it maintains within 2-3, it's the same even after $75 \mathrm{~d}$ leaching. This illustrates that waste rock itself produces large quantity of acid, as a result, the value of leachate is lower than the $\mathrm{pH}$ value of acid rain. Moreover, the value of leachate is lower than the value of waste rock due to the import of $\mathrm{H}^{+}$in acid rain, which reduces $\mathrm{pH}$ value, on the other hand, $\mathrm{Na}^{+}, \mathrm{Ca}^{2+}, \mathrm{Mg}^{2+}$ and other positive ions displace the exchangeable $\mathrm{H}^{+}$ adsorbed onto the waste rock surface and enter the leachate, and the $\mathrm{pH}$ is lowered as a result.

Seen from the leaching time, the values of leachate are close regardless the $\mathrm{pH}$ value of initial leachate. This indicates waste rock has relatively strong acid producing capacity in natural rainfall.
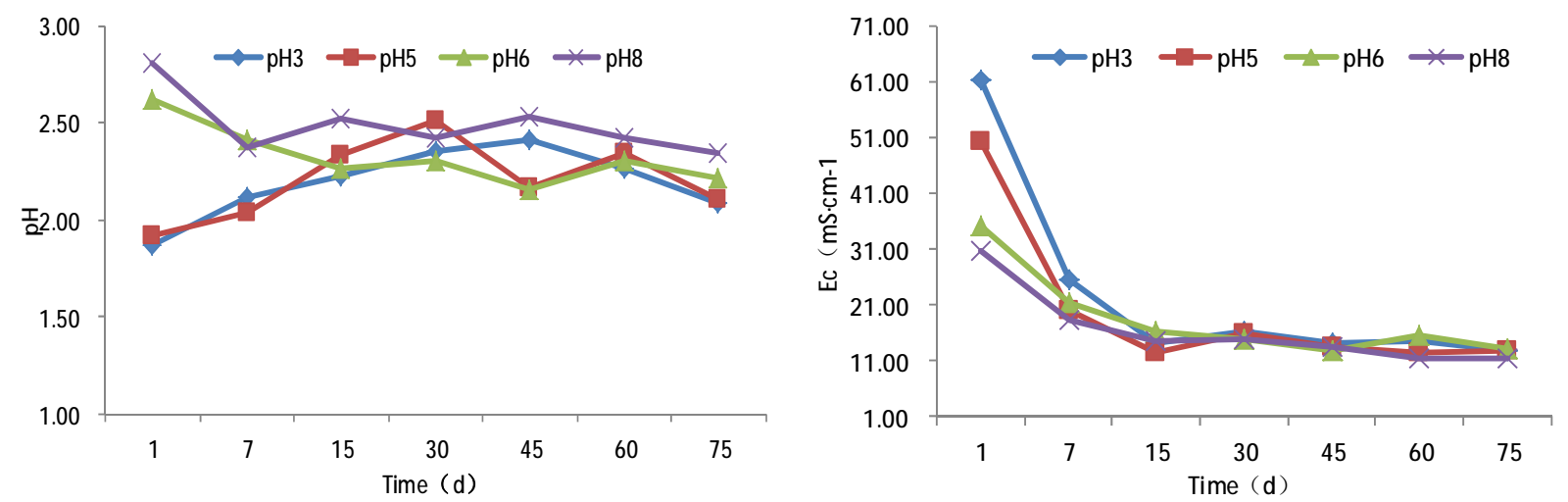

Fig2 Curve of variation of leachate $\mathrm{pH}$ of waste rock under different $\mathrm{pH}$ and Ec values over time

Law of variation of leachate (Ec) over time. The law of variation of Ec can be seen from Fig 2, When $\mathrm{pH}$ remains unchanged, Ec value is relatively high as more salt is leached at the early stage. The electric conductivity is relatively low at the initial stage of leaching, the value of leachate reduces slowly in $15 \mathrm{~d}$, and the decreasing trend and degree are relatively stable. During the leaching process, the electric conductivity of leachate reduces gradually, and the difference is relatively big before and after. The electric conductivity of the leachate reduces rapidly at the initial stage, and then the reducing speed turns stable. Meanwhile, Ec value of $\mathrm{pH}_{3}$ leachate is the highest, but Ec value reduces gradually with the increase of $\mathrm{pH}$ value of the added liquid. The value of added liquid is equivalent to 
the values of $\mathrm{pH}_{6}$ leachate and $\mathrm{pH}_{8}$ leachate. It indicates the ion concentration in the leachate is relatively stable.

Characteristics of $\mathrm{Cu}$ release. As shown in Fig 3, the leaching speed is relatively high at the early stage of leaching, subsequently $\mathrm{Cu}$ content in leachate decreases sharply and gradually transfers to slow decrease. Under different conditions, or under the condition of the same value, there is eminent difference in the leaching quantity in different leaching periods. Seen from the total amount, after $75 \mathrm{~d}$ leaching, the leaching amount is the highest under $\mathrm{pH}_{3}$ condition, the leachate with $\mathrm{pH}$ value of 5 comes the second, the total quantity of leaching is minimum where $\mathrm{pH} 8$ leachate is used, indicating it's more favorable for the leaching of waste rock under strong acid condition.
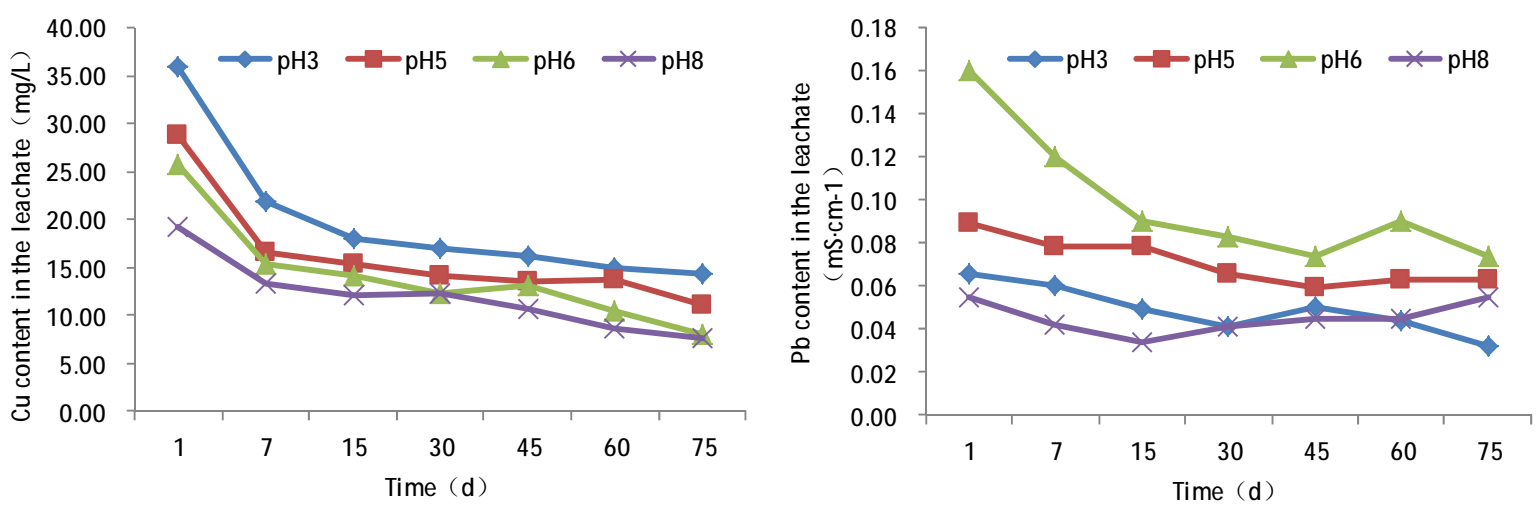

Fig3 Curve of $\mathrm{Cu}$ and $\mathrm{Pb}$ content in leachate with the variation of $\mathrm{pH}$ and leaching time

Characteristics of $\mathbf{P b}$ release. Compared with $\mathrm{Cu}$, the leaching quantity of $\mathrm{Pb}$ is much lower. It's relevant to its chemical properties. In general condition, Pbis almost unreactive with dilute hydrochloric acid and dilute sulfuric acid, and the solubilities of the products $\mathrm{PbCl}_{2}$ and $\mathrm{PbSO}_{4}$ are small; however, dilute nitric acid is soluble, and can produce soluble $\mathrm{Pb}\left(\mathrm{NO}_{3}\right)_{2}$. Both the oxide and hydroxide of $\mathrm{Pb}$ are amphoteric, high-peroxide $\mathrm{PbO}_{2}$ and $\mathrm{Pb}(\mathrm{OH})_{4}$ are mainly acidic, low-peroxide $\mathrm{PbO}$ and $\mathrm{Pb}(\mathrm{OH})_{2}$ are mainly alkalic, namely, they are soluble in both acid and alkali, however, $\mathrm{PbS}$ isn't soluble in dilute hydrochloric acid but soluble in dilute nitric acid and concentrated hydrochloric acid.

As shown in Fig 3, within the same period of time, $\mathrm{Pb}$ content in $\mathrm{pH} 3$ leachate is remarkably higher than that in $\mathrm{pH}_{5}, \mathrm{pH}_{6}$ and $\mathrm{pH}_{8}$ leachate. $\mathrm{Pb}$ content in leachate of different $\mathrm{pH}$ values shows a descending trend over time.

Characteristics of $\mathrm{Zn}$ release. $\mathrm{Zn}$ exists in waste rock mainly in the form of $\mathrm{ZnS}, \mathrm{Zn}$ may react with chloride to achieve strong complex compounds which accelerate dissolution. During the $75 \mathrm{~d}$ leaching period, the total leaching quantity of $\mathrm{Zn}$ is the highest $(11.32 \mathrm{mg} / \mathrm{L})$ under the condition of $\mathrm{pH}_{3}$, and it comes the second $(9.43 \mathrm{mg} / \mathrm{L})$ under the condition of $\mathrm{pH}_{5}$, and it's the lowest $(7.12 \mathrm{mg} / \mathrm{L})$ under the condition of $\mathrm{pH}_{8}$.

As shown in Fig 4, the law of variation of $\mathrm{Zn}$ concentration of leachate over time is: $\mathrm{Zn}$ release is very fast at the initial stage, and then turns mild.
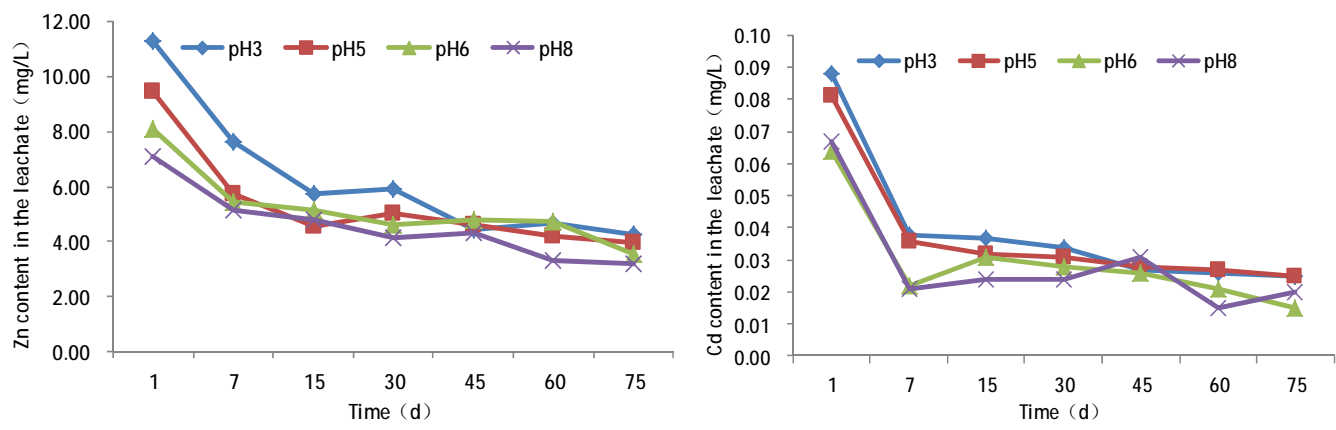

Fig 4 Curve of $\mathrm{Zn}$ and $\mathrm{Cd}$ content in leachate with the variation of $\mathrm{pH}$ and leaching time

Characteristics of Cd release. As shown in Fig 4, Cd tends to be released the most easily under the condition of $\mathrm{pH}_{3}$ in the $75 \mathrm{~d}$ leaching period, it comes the second under the condition of $\mathrm{pH}_{5}$, and 
it's the weakest under the condition of $\mathrm{pH}_{8}$. As shown in Fig 6, the law of variation of $\mathrm{Zn}$ concentration of leachate over time is: $\mathrm{Zn}$ release is very fast at the initial stage, and then turns mild. This is relevant to rapid oxygenolysis of blende which contains $\mathrm{Cd}$.

Characteristics of As release. As shown in Fig 5, pH value of leachate has great influence on the leaching quantity in the same leaching period. Seen from the total amount, As content of $\mathrm{pH}_{3}$ leachate is the highest, it comes the second in case of $\mathrm{pH}_{5}$, and the least in case of $\mathrm{pH}_{8}$.

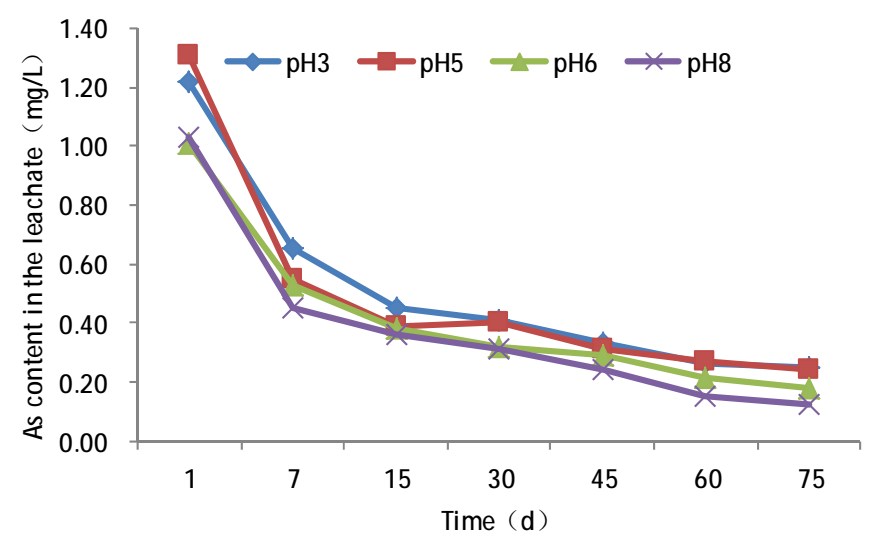

Fig 5 Curve of As content in leachate with the variation of $\mathrm{pH}$ and leaching time

\section{Conclusions}

Acid rain leaching method is adopted in this paper to conduct dynamic leaching experiments on the waste rock in Dexing Copper Mine, for the purpose of finding out the law of variation of heavy metal contents in leachate over time. The result of study is shown below:

1) As for the waste rock of Dexing Copper Mine, the value of leachate falls between 1.9-3.9, indicating that waste rock of Dexing Copper Mine have relatively strong acid producing capacity under natural rainfall.

2) With the increase of $\mathrm{pH}$ value of added liquid, Ec value decreases gradually, and it's relatively different before and after adding. The electric conductivity of the leachate reduces rapidly at the beginning, and then the reducing speed turns stable.

3) 5 heavy metal elements $(\mathrm{Cu}, \mathrm{Pb}, \mathrm{Zn}, \mathrm{Cd}$ and $\mathrm{As})$ in the waste rock are the most easily to be released and migrated under the action of strong acid with the lowest $\mathrm{pH}$, and the leaching quantity is relatively low if leached when the leachate $\mathrm{pH}$ is nearly neutral. The release quantities of the 5 heavy metals are constant over time, and the release process can be divided into two stages: the first stage is a rapid release process. The release quantity of the 5 heavy metals increases rapidly over time within $7 \mathrm{~d}$, but the speed of increase slows down continuously. The second stage is a slow release process, during which the release quantities of the 5 heavy metals increase slowly over time within $7 \mathrm{~d}$, indicating the release speed of heavy metals tends to become stable.

\section{Acknowledgements}

The project was financially supported by the International Technology Cooperation Special Project (2012DFA90500): Research on Key Technology Cooperation for Comprehensive Improvement to Acidic Pollution in Metallic Mine Dump.

\section{References}

[1] Lin Meiqun, Ma Shaojian, Wang Guifang,et al. Simulation Study on Influence of Environmental Factors on Release of Heavy Metal Ions out of Sulfide Ore Tailings. Metal Mine, 6(2008):108-111.(In Chinese) 
[2] Rao Yunzhang, Hou Yunbing. Study on law of acidification of wastewater in tailings reservoir and heavy metals pollution. Journal of Liaoning Technical University(Natural Science Edition), 3(2004):430-432. (In Chinese)

[3] Wang Jianbing, Chen Zhipeng, Duan Mingxing, et al. Leaching characteristics and release law of heavy metals from the mining mullock and tailings in nonferrous metal mining industry. Ecology and Environment Sciences, 2(2014):300-306. (In Chinese)

[4] Lei Liangqi, Song Cian, Xie Xiangli. et al The Prevention and Treatment Technology of Geochemical Engineering on Acid Mine Drainage. Metal Mine,12(2009):114-116. (In Chinese)

[5] Bai Runcai, Libing, Li Sanchuan, et al. Development and Status of the Treatment Technology for Acid Mine Drainage.Journal of Yangtze River Scientific Research Institute, 2(2015):14-19. (In Chinese)

[6] Zuo Lina, He Qianfeng.The state-of-art and progress of the treament techinology for acid mine wastewater. Environmental Engineering, 5(2013):35-38. (In Chinese) 